\title{
Uveal melanoma survival rates after single dose stereotactic radiosurgery
}

\author{
A. FURDOVA ${ }^{1, *}$, P. BABAL ${ }^{2}$, D. KOBZOVA ${ }^{2}$, P. ZAHORJANOVA ${ }^{1}$, K. KAPITANOVA ${ }^{1}$, M. SRAMKA ${ }^{3}$, G. KRALIK ${ }^{4}$, R. FURDA ${ }^{5}$, V. KRASNIK ${ }^{1}$
}

${ }^{1}$ Department of Ophthalmology, Faculty of Medicine, Comenius University in Bratislava, Slovakia; ${ }^{2}$ Department of Pathology, Faculty of Medicine, Comenius University in Bratislava, Slovakia; ${ }^{3}$ Department of Stereotactic Radiosurgery, St. Elisabeth Cancer Institute, St. Elisabeth University College of Health and Social Work, Bratislava, Slovakia; ${ }^{4}$ Department of Medical Physics, Faculty of Medicine, Slovak Medical University, Bratislava, Slovakia; ${ }^{5}$ Department of Information Systems, Faculty of Management, Comenius University, Bratislava, Slovakia

*Correspondence: afrf@mail.t-com.sk

Received December 10, 2017 / Accepted March 21, 2018

\begin{abstract}
This paper presents the long-term results of single dose stereotactic radiosurgery for intraocular uveal malignant melanoma, and summarizes the results of the retrospective study in 170 Slovak patients. A group of uveal melanoma patients (149 choroidal melanoma, 21 ciliary body melanoma) from 20 to 92 years of age with 59 year median were treated in 2001-2016. There were 81 males (47.7\%) and 89 females 89 (52.3\%). The median overall follow-up time was three years. The median tumor volume at baseline was $0.5 \mathrm{~cm} 3$ (ranging from 0.2 to $1.6 \mathrm{~cm} 3$ ). The therapeutic dose was $35.0 \mathrm{~Gy}$ by $99 \%$ of dose volume histogram. The survival after single dose stereotactic radiosurgery was $96 \%$ in one year, $93 \%$ in two years, $84 \%$ in five years, $80 \%$ in seven years and $52 \%$ in eleven years. Secondary enucleation was necessary for 22 patients because of secondary glaucoma complication. The enucleation free interval ranged from one to six years. The survival rates in five year intervals and necessity of secondary enucleation due to complications after single dose stereotactic radiosurgery is comparable to other techniques.
\end{abstract}

Key words: uveal melanoma, linear accelerator, stereotactic radiosurgery, survival, intraocular tumor

Uveal melanoma is the most common and the most aggressive primary intraocular malignancy in adults. The mean age-adjusted incidence of uveal melanoma in the United States is approximately 4.3 new cases per million people, the incidence in Slovakia is from 2 to 6 new cases per million inhabitants per year $[1,2]$.

Age and tumor volume (size) were determined prognostic indicators for uveal melanoma therapy. The molecular profile of the uveal melanoma differs in cutaneous and mucosal melanoma.

Ophthalmological examination and diagnostic tools, such as ultrasound, optical coherence tomography, computed tomography (CT), magnetic resonance imaging (MRI) and positron emission tomography (PET/CT) have led to significant advances in the diagnosis of primary uveal melanoma. Radiotherapy (brachytherapy and other modalities - proton beam irradiation and stereotactic radiotherapy) has become the preferred method of treatment for the majority of patients with uveal melanoma. Stereotactic radiosurgery (SRS) of extra-cerebral lesions, such as uveal melanoma, has been used in the last two decades for treatment of small and medium stage posterior uveal melanoma because it offers good local control. Survival rates are comparable to other types of therapy [3-5].

The single dose SRS is a relatively rare method in treatment of choroidal melanoma. Image fusion of a contrast-enhanced MRI and CT is used for treatment planning coordinates. This treatment is used as single dose SRS with one fraction of 35.0 Gy administered with spatial accuracy by collimation.

The team of specialists consists of an ophthalmologist, neurosurgeon, medical physicist and a radiation oncologist. All were responsible for SRS planning and image fusion of a contrast-enhanced MRI and CT images is used for treatment planning coordinates. Fusion of the images from these imaging techniques is suitable for accurately specifying anatomical structures and differentiating gross tumor volume (GTV) and mass from healthy tissue and the most critical adjacent structures (optic chiasm, brain stem, skin of the head, bilateral optic nerves and lenses). Precise planning is most important for determining the stereotactic coordinates of radiation beams to be applied in GTV and irradiation of critical structures by inappropriate doses can lead to loss of vision or other complications and can reduce later life quality [6]. 
The ability to metastasize hematogenously is well-known in choroidal melanoma, and this frequently goes to the liver [7-9]. Patients after both conservative and surgical ocular treatment are followed-up for metastases in six monthly intervals by liver function tests, and/or imaging methods.

Survival prognostic factors are; (1) clinical predictors (tumor maximum elevation, basal diameter, ciliary body involvement, extra-ocular infiltration), (2) histopathological predictors (epithelioid melanoma has worse prognosis), and (3) high mitotic count and genetic predictors. Although effective local therapies have been developed over the past 30 years, five-year survival rates have not changed, and over $50 \%$ of patients develop metastases.

The aim of this study is to determine the length of time before metastasis diagnosis after stereotactic radiosurgery, and the rates and sites of metastasis discovered during patient follow-up.

\section{Patients and methods}

We analyzed data in a retrospective study of patients with intraocular uveal melanoma T1 to T3 stages who underwent SRS at linear accelerator (Model LINAC C 600 C/D Varian [Varian Medical Systems Inc., Palo Alto, California, USA] with $6 \mathrm{MeV}$ photons in 2001-2016. The manuscript does not report results of experimental investigations on human subjects due to the Declaration of Helsinki, and our study was approved by the Ethics Committee at the University Teaching Hospital in Bratislava.

Treatment protocol. All patients with uveal melanoma treated in 2001-2016 were included. Patients were not randomized either to radical (enucleation) or to "conservative" procedures, because treatment was determined exclusively on a patient-to-patient basis. Tumor stage, volume, maximum elevation, localization, presence of secondary retinal detachment, general status, age, gender, the functional tests (visual acuity, perimetry, ultrasound) were all considered. All patients were actively involved in the decision on their therapeutic procedure after the possible post-operative complications were discussed.

Data analysis. The tumor volume was calculated using the formula: volume $=\pi / 6 \times$ length $\times$ width $\times$ height. Tumors were divided into three groups: small - less than $0.5 \mathrm{~cm}^{3}$, medium - 0.5 to $1.0 \mathrm{~cm}^{3}$, and large - over $1.0 \mathrm{~cm}^{3}$.

Immobilization of the affected eye was achieved by surgical fixation of the eye-globe to the stereotactic Leibinger frame. Sutures were placed under local anesthesia to four direct extraocular muscles through conjunctiva and through the lids. The stereotactic frame was fixed to the head and the sutures were tied to the stereotactic frame. The patient underwent CT and MRI examination with the immobilized eye-globe to the frame. The stereotactic treatment planning after fusion of CT and MRI was optimized according to the critical structures - lenses, optic nerves and chiasm. Tumor volume calculation was based on the ROI (region of interest) of the tumor. The planned therapeutic dose into the tumor mass was 35.0 Gy by $99 \%$ of DVH (dose volume histogram).

On the sa me afternoon, the patient underwent irradiation at linear accelerator. The doses to the critical structures were below $8.0 \mathrm{~Gy}$ for the optic nerve and the optic disc, and 10.0 Gy to the anterior segment of the eye due to SRS planning scheme. Sutures and frame were removed under local anesthesia.

Follow-up. Patients were followed-up after three months by an ophthalmologist (biomicroscopy, ophthalmoscopy, aplanation tonometry, ultrasound, Optical Coherence Tomography), and sent for orbit MRI after six months. Following the first visit after stereotactic radiosurgery, patients were seen by their oncologist every six months for metastases screening (liver ultrasound, abdominal ultrasound, liver function test; once per year chest X-ray). Since January 2014, every patient has had a whole body PET/CT (Positron Emission Tomography) before stereotactic radiosurgery to exclude liver metastases. The disease free interval was defined as the time from treatment until the development of metastases. Patients were seen in three monthly intervals in the first year after the SRS, later in six monthly intervals following SRS; and five years after SRS they were requested to attend each year for complete examination.

Statistical methods. We used single linear regression, basic statistical methods and the non-parametric method to estimate the probability of survival after given time intervals.

\section{Results}

Patients' characteristics. A total of 170 consecutive charts of patients with uveal melanoma (149 choroidal melanoma - 87.6\%, 21 ciliary body melanoma - 12.4\%) treated with single dose SRS were reviewed. Patient age ranged from 21 to 90 years with a median of 57 years. The number of males was $81(47.7 \%)$ and number of females 89 (52.3\%). Median tumor volume at baseline was $0.5 \mathrm{~cm}^{3}$, with range from 0.2 to $1.6 \mathrm{~cm}^{3}$. The therapeutic dose was $35.0 \mathrm{~Gy}$ by $99 \%$ of dose volume histogram (DVH). The median of the maximal dose applied was $49.0 \mathrm{~Gy}$ (range from 37.0 to $51.0 \mathrm{~Gy}$ ). The number of the small uveal melanomas was 39 (23\%), 97 were medium (57\%) and 34 large (20\%) (Suppl. Table 1).

Secondary enucleation was necessary in 22 patients (12.9\%) due to secondary glaucoma. In this subgroup, liver metastasis developed in 20 patients $(90.1 \%)$ The enucleation free interval ranged from one to six years, and Figures 1 and 2 demonstrate patient examination findings before the irradiation, planning scheme and enucleated eye-globe.

Survival analysis. The survival time of 170 patients was from 0.25 to 15 years. The median overall follow-up time was three years. We calculated three Kaplan-Meier survival curves. In the first survival curve, the overall survival after SRS was $96 \%$ in one year, $93 \%$ in two years, $84 \%$ in five years, $80 \%$ in seven years and $52 \%$ in eleven years (Figure $3 \mathrm{~A}$ ). The second survival curve compared small and large tumors 

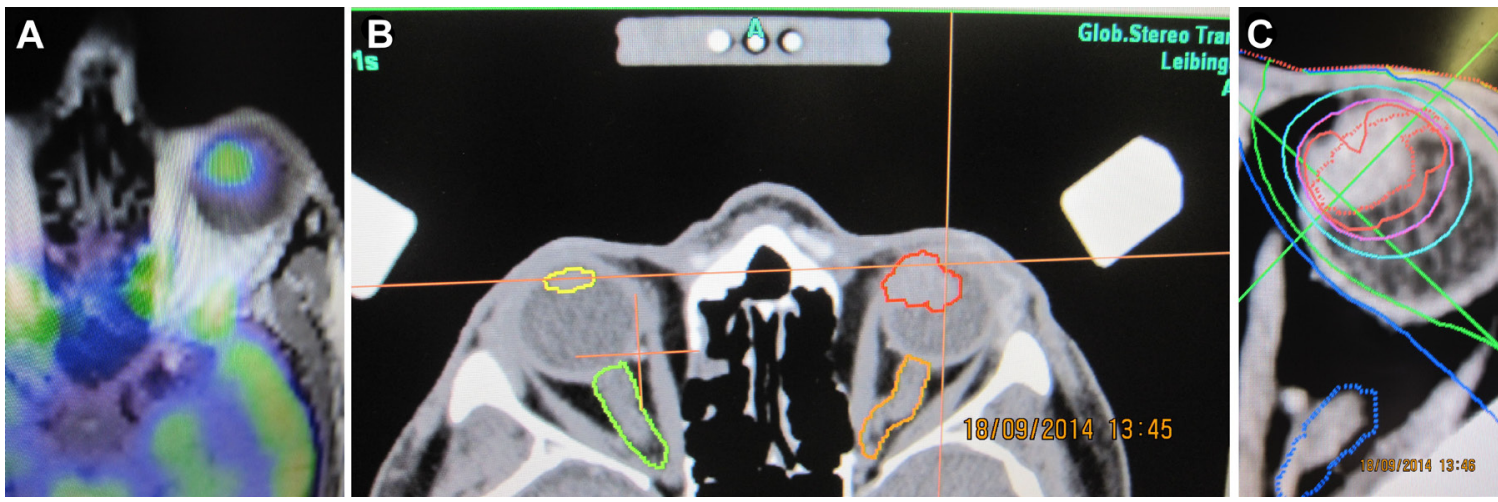

Figure 1. The patient's status in 2014: A) PET/CT finding of patient with ciliary body melanoma before SRS; B) MRI finding with plotted tumor (red) and critical structures: lens (yellow), optic nerves (green, orange); C) Stereotactic planning scheme.
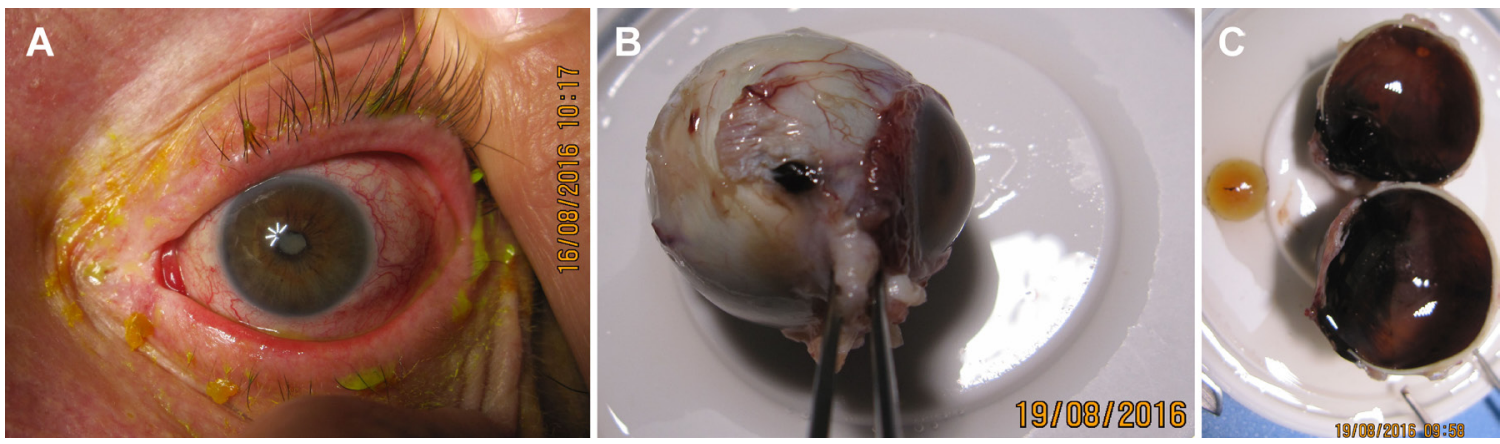

Figure 2. The patient's status in 2016: A) patient 2 years after SRS underwent enucleation due to painful secondary glaucoma: external photograph of anterior segment before enucleation; B) eye-globe after enucleation with extrascleral extension; C) dissected eye-globe.
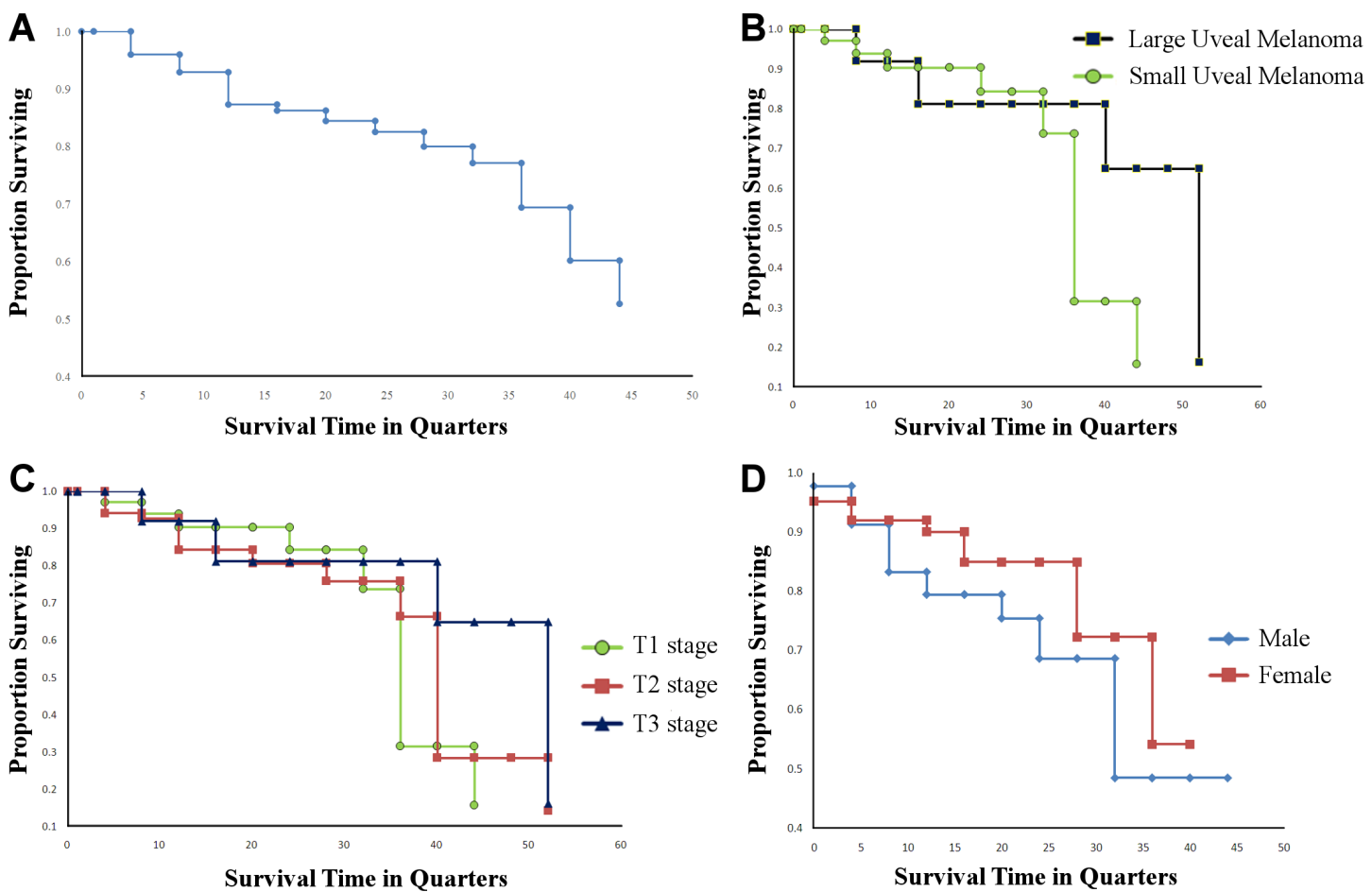

Figure 3. A) Survival curves - in group of 170 patients with uveal melanoma after SRS; B) survival curves - the comparison of the small and large tumors; C) survival curves - the comparison of the stages T1, T2, and T3; D) Cox regression - survival curves the patient group by gender. 
(Figure $3 \mathrm{~B}$ ) and the third compared $\mathrm{T} 1, \mathrm{~T} 2$, and $\mathrm{T} 3$ stages (Figure 3C).

We calculated one Cox proportional-hazards regression by gender (Figure 3D). Two predictors were considered: tumor volume and age of patient at the time of stereotactic radiosurgery. The calculation results confirmed that only one predictor, age by male ( $\mathrm{p}=0.0572$ with Risk Ratio 1.0488 ) was closest to being a significant prognostic factor. However, its $\mathrm{p}$ value was more than 0.05 and there were no other significant prognostic factors in this Cox proportional-hazards regression for survival analysis. The other calculated predictors were: age by female, $\mathrm{p}=0.8107$ with Risk Ratio 1.0066 , tumor volume by male, $\mathrm{p}=0.6210$ with Risk Ratio 0.4358 , and tumor volume by female, $\mathrm{p}=0.3103$ with Risk Ratio 0.1765. The analysis indicated that none of the four predictors were statistically significant by gender comparison.

Follow-up. In the group of patients with small tumors who developed metastases, the interval after SRS was over five years, and in the patient group with large melanoma who developed metastases, the interval after SRS was less than three years. Finally, tumor volume reduction review after the initial six months following SRS ranged from 6 to 110 months.

We analyzed acute side effects on the eye-lids and anterior eye segment following SRS. The SRS planning scheme ensured that doses to the critical structures were below $8.0 \mathrm{~Gy}$ for the optic nerve (median 2.0 Gy), below 12.0 Gy (median $3.0 \mathrm{~Gy}$ ) for the optic disc and below $10.0 \mathrm{~Gy}$ (median $5 \mathrm{~Gy}$ ) to the anterior segment of the eye. Long-term side effects such as cataracts and maculopathy were noted in patients with tumors less than $3.0 \mathrm{~mm}$ from the macula or ciliary body. Tumor local control was successful in $95 \%$ of patients two years after SRS and in $75 \%$ of patients three years after SRS.

Late complications 24 months after SRS were observed: macular destruction because of scarring around the tumor in $55 \%$ patients, optic nerve atrophy in $15 \%$, partial lens opacity in $30 \%$, total cataract in $5 \%$, vitreous hemorrhage in $5 \%$, secondary glaucoma in $15 \%$, and central retinal vein thrombosis in $10 \%$. Secondary enucleation was necessary in 22 patients $(12.9 \%)$ due to secondary glaucoma. Melanoma was histopathologically verified in all enucleated eyes: spindle cell type A in 16 (72.7\%) patients; spindle cell type B in two (9.1\%) and epitheloid type in four (18.2\%) patients. The BRAF mutation was negative in all these patients.

\section{Discussion}

Management of posterior uveal melanoma depends on tumor location, extent and size, on visual acuity on presentation and on systemic status [10].

The tendency away from enucleation towards eye-globe sparing techniques is seen in uveal melanoma patient management. The alternatives are: a) observation, b) transpupillary thermotherapy, c) block-excision, d) endo-resection with pars plana vitrectomy, e) brachy-therapy with a variety of radioisotopes, f) radiotherapy - proton beam irradiation, g) Leksell Gamma Knife and h) stereotactic radiosurgery [11-13].

Randomized, multi-center clinical trials conducted by the Collaborative Ocular Melanoma Study (COMS) group showed no difference in long-term survival rates of patients treated with plaque radiotherapy or enucleation of medium-sized tumors (basal diameter $<16 \mathrm{~mm}$ and apical height $2.5-10 \mathrm{~mm}$ ) [14]. There was no mortality benefit with pre-enucleation radiotherapy for large tumors (basal diameter $\geq 16 \mathrm{~mm}$ and apical height $\geq 2 \mathrm{~mm}$ or any basal diameter with apical height $\geq 10 \mathrm{~mm}$ ) [15].

Proton beam radiotherapy is another form of radiation treatment used for posterior uveal melanoma, and this is comparable to plaque radiotherapy for tumor control, visual outcome and systemic prognosis [16]. Stereotactic photon beam radiation therapy using cyber knife, gamma knife or linear accelerator can also be used in choroidal melanoma management. The local tumor control, visual outcome and survival of patients undergoing stereotactic photon beam radiation therapy are equivalent to those undergoing proton beam radiotherapy [17].

The COMS study showed no difference in uveal melanomarelated metastasis and death based on gender. However, some reports suggest a better prognosis in females; with twice the mortality rate in males in the first 10 years of posterior uveal melanoma diagnosis [18]. Our study, however, determined no difference in prognosis due to age.

The efficacy of SRS for uveal melanoma has been proven in different studies with local tumor control rates reported over 90\% [19-21]. High rates of local control can be also achieved with five-year control rates exceeding $95 \%$ in patients treated with proton-beam irradiation [22]. Reported case series suggest that SRS can have similar rates for local tumor control, metastasis, mortality and complications compared to brachytherapy. These findings suggest SRS's role in the treatment of selected uveal melanoma cases $[23,24]$. The eye-globe preserving treatment with LINAC based stereotactic irradiation is feasible and well-tolerated in patients with medium sized and unfavorably located uveal melanoma [25].

There are few large, prospective and randomized trials with mortality statistics for medium-sized melanomas treated by brachytherapy, enucleation or SRS [26-28]. The gamma knife radiosurgery and SRS is a proper alternative in treating uveal melanoma in patients with lesions which are inappropriate for conventional brachytherapy. Patients receive a single non-fractionated dose of stereotactic radiation, with maximum and peripheral doses at 40-75 Gy and 16.5-30 Gy. Eye retention is one of the main goals of conservative treatment, but secondary enucleation is indicated in some patients due to complications after irradiation; including secondary neo-vascular glaucoma [24]. According to presented results, a single one-day session SRS with 35.0 Gy is recommended for treating small and medium stage melanoma [28].

Metastatic melanoma has four important prognostic death factors. The first factor is the size of the tumor: the larger 
the tumor, the worse the prognosis. The second factor is the location of the tumor. The third factor is the age of the patient at the time of diagnosis: the older the patient, the worse the short-term survival prognosis. And the fourth factor is the extrascleral tumor extension [29]. The obvious disadvantages of enucleation are eye-globe preservation and useful vision in patients treated conservatively with SRS.

The limit of metastatic spread is also questionable. Some observational studies comparing irradiation and enucleation have reported no significant differences in survival rates [23, 28]. Another study also indicated no significant difference in comparison of five-year mortality rates in patients treated by plaque radio-therapy and enucleation [26].

Studies in the past decades have promoted treatment with proton irradiation, and this can be highly successful in achieving local control of intraocular melanoma. The overall rates of metastatic disease are comparable to those observed after enucleation when this treatment is implemented and it is further recommended that enucleation should be limited to patients with large tumors. The stricken eye is unlikely to be salvaged by non-destructive treatment, such as irradiation.

The refinement of current methods and development of new techniques should continually improve the positive outlook of the uveal melanoma patients. The survival strategies in these studies proposed the use of single-dose stereotactic radiotherapy with combined tumor resection. This can increase tumor control with fewer radiation complications than mono-treatment with single-dose stereotactic radiotherapy $[30,31]$.

Multidisciplinary teams must cooperate both in patient treatment and post-treatment management because no survival benefit from early metastasis detection has currently been documented and no effective adjuvant systemic therapy has been demonstrated to reduce the risk of metastases [32, 33].

The uveal melanoma TNM stage is an important prognostic factor. In a study of 7,731 patients with posterior uveal melanoma based on the American Joint Committee on Cancer T-category classification, the risk of metastasis and death increased twofold with each increasing tumor category, and the 10 -year metastatic rate was $15 \%$ for T1, 25\% for T2, $49 \%$ for T3 and $63 \%$ for T4 tumors [34]. Kang et al. reported the overall 5-year survival rate in group of patients after Gamma Knife surgery for uveal melanoma was $90.9 \%$ (20 of 22 patients) [35]. They analyzed patient survival according to age, sex, tumor volume, and margin dose; however, no relationship was found among these variables $(p>0.05)$ [35]. Our study revealed the overall 5 -year survival rate was $84 \%$, and no relationship was also found in age, gender, and tumor volume prediction $(\mathrm{p}>0.05)$.

Arnett et al's study [36] had the following findings; median age at diagnosis was 70 years and median follow-up was 26.4 months. Primary ocular melanoma was diagnosed in $17(61 \%)$ patients (stage T2a-T4e). The average maximum dose and dose to margin were 41 and $21 \mathrm{~Gy}$, respectively. The mean dose to the optic nerve was $12.6 \mathrm{~Gy}$. The 5-year survival for subjects presenting with primary ocular melanoma lesions was $90 \%$ and only 1 patient required enucleation after radiation treatment [36].

This compares with our study where the average maximum dose was $49 \mathrm{~Gy}$, the overall 5-year survival rate was $84 \%$, and enucleation was necessary in $12.9 \%$.

It is very hard to clinically differentiate adenocarcinomas and adenomas derived from pigmented ciliary epithelium from uveal melanoma. In addition, BRAF gene mutation has been confirmed in skin malignant melanomas, and Mori et al.[37] identified BRAF V600E mutations in four of five adenocarcinoma samples, but not in the 11 uveal melanoma samples [37]. However, findings in other group studies failed to confirm that the uveal melanoma should also contain BRAF mutations because it has similar origin to skin melanoma. Finally, our study [38] also established negative BRAF results in enucleated eyes with uveal melanoma [38].

\section{Conclusion}

Survival rates in patients with posterior uveal melanoma treated at linear accelerator are comparable to other treatment methods. According to the results the single dose SRS with $35.0 \mathrm{~Gy}$ is valuable method to treat small and medium stage uveal melanoma. In this study the survival rates in five year interval and necessity of secondary enucleation, due to complications after single dose SRS, is comparable to other treatment modalities.

Supplementary information is available in the online version of the paper.

Acknowledgements: This work was supported by APVV-170369 and KEGA 016UK-4/2018.

\section{References}

[1] SINGH AD, TURELL ME, TOPHAM AK. Uveal melanoma: trends in incidence, treatment, and survival. Ophthalmology 2011; 118: 1881-1885. https://doi.org/10.1016/j.ophtha.2011.01.040

[2] FURDOVA A, OLAH Z, SVETLOSAKOVA Z, KUSENDA P. [The current state of the evidence of malignant tumors of the eye and its adnexa (dg. C69) in the Slovak Republic and in the Czech Republic]. Cesk Slov Oftalmol 2012; 68: 195-201.

[3] FURDOVA A, HORKOVICOVA K, JUSTUSOVA P, SRAMKA M. Is it sufficient to repeat LINEAR accelerator stereotactic radiosurgery in choroidal melanoma? Bratisl Lekárske Listy 2016; 117: 456-462.

[4] COHEN VM, CARTER MJ, KEMENY A, RADATZ M, RENNIE IG. Metastasis-free survival following treatment for uveal melanoma with either stereotactic radiosurgery or enucleation. Acta Ophthalmol Scand 2003; 81: 383-388. 
[5] DAMATO B, KACPEREK A, CHOPRA M, CAMPBELL IR, ERRINGTON RD. Proton beam radiotherapy of choroidal melanoma: the Liverpool-Clatterbridge experience. Int J Radiat Oncol Biol Phys 2005; 62: 1405-1411. https://doi. org/10.1016/j.ijrobp.2005.01.016

[6] FURDOVA A, STRMEN P, WACZULIKOVA I, CHORVATH M, SRAMKA M et al. One-day session LINAC-based stereotactic radiosurgery of posterior uveal melanoma. Eur J Ophthalmol 2012; 22: 226-235. https://doi.org/10.5301/ EJO.2011.7733

[7] COLLABORATIVE OCULAR MELANOMA STUDY GROUP. Assessment of metastatic disease status at death in 435 patients with large choroidal melanoma in the Collaborative Ocular Melanoma Study (COMS): COMS report no. 15. Arch Ophthalmol 2001; 119: 670-676.

[8] DIENER-WEST M, REYNOLDS SM, AGUGLIARO DJ, CALDWELL R, CUMMING K et al. Screening for metastasis from choroidal melanoma: the Collaborative Ocular Melanoma Study Group Report 23. J Clin Oncol 2004; 22: 2438-2444. https://doi.org/10.1200/JCO.2004.08.194

[9] DIENER-WEST M, REYNOLDS SM, AGUGLIARO DJ, CALDWELL R, CUMMING K et al. Development of Metastatic Disease After Enrollment in the COMS Trials for Treatment of Choroidal Melanoma: Collaborative Ocular Melanoma Study Group Report No. 26. Arch Ophthalmol 2005; 123: 1639-1643.

[10] KALIKI S, SHIELDS CL. Uveal melanoma: relatively rare but deadly cancer. Eye (Lond) 2017; 31: 241-257. https://doi. org/10.1038/eye.2016.275

[11] HENDERSON MA, SHIRAZI H, LO SS, MENDONCA MS, FAKIRIS AJ et al. Stereotactic radiosurgery and fractionated stereotactic radiotherapy in the treatment of uveal melanoma. Technol Cancer Res Treat 2006; 5: 411-419. https://doi. org/10.1177/153303460600500409

[12] DIECKMANN K, GEORG D, BOGNER J, ZEHETMAYER $\mathrm{M}$, PETERSCH B et al. Optimizing LINAC-based stereotactic radiotherapy of uveal melanomas: 7 years' clinical experience. Int J Radiat Oncol 2006; 66: S47-S52. https://doi. org/10.1016/j.ijrobp.2006.01.005

[13] MOSCI C, MOSCI S, BARLA A, SQUARCIA S, CHAUVEL $P$ et al. Proton beam radiotherapy of uveal melanoma: Italian patients treated in Nice, France. Eur J Ophthalmol 2009; 19: 654-660.

[14] COLLABORATIVE OCULAR MELANOMA STUDY GROUP. The COMS randomized trial of iodine 125 brachytherapy for choroidal melanoma: V. Twelve-year mortality rates and prognostic factors: COMS report No. 28. Arch Ophthalmol 2006; 124: 1684-1693. https://doi.org/10.1001/ archopht.124.12.1684

[15] HAWKINS BS, COLLABORATIVE OCULAR MELANOMA STUDY GROUP. The Collaborative Ocular Melanoma Study (COMS) randomized trial of pre-enucleation radiation of large choroidal melanoma: IV. Ten-year mortality findings and prognostic factors. COMS report number 24 . Am J Ophthalmol 2004; 138: 936-951. https://doi.org/10.1016/j. ajo.2004.07.006

[16] GRAGOUDAS ES. Proton beam irradiation of uveal melanomas: the first 30 years. The Weisenfeld Lecture. Invest Ophthalmol Vis Sci 2006; 47: 4666-4673. https://doi. org/10.1167/iovs.06-0659
[17] DUNAVOELGYI R, DIECKMANN K, GLEISS A, SACU S, KIRCHER $\mathrm{K}$ et al. Local tumor control, visual acuity, and survival after hypofractionated stereotactic photon radiotherapy of choroidal melanoma in 212 patients treated between 1997 and 2007. Int J Radiat Oncol Biol Phys 2011; 81: 199-205. https://doi.org/10.1016/j.ijrobp.2010.04.035

[18] ZLOTO O, PE'ER J, FRENKEL S. Gender differences in clinical presentation and prognosis of uveal melanoma. Invest Ophthalmol Vis Sci 2013; 54: 652-656. https://doi. org/10.1167/iovs.12-10365

[19] MUELLER AJ, TALIES S, SCHALLER UC, HORSTMANN G, WOWRA B et al. Stereotactic radiosurgery of large uveal melanomas with the gamma-knife. Ophthalmology 2000; 107: 1381-1387.

[20] KREMA H, SOMANI S, SAHGAL A, XU W, HEYDARIAN $M$ et al. Stereotactic radiotherapy for treatment of juxtapapillary choroidal melanoma: 3-year follow-up. Br J Ophthalmol 2009; 93: 1172-1176. https://doi.org/10.1136/ bjo.2008.153429

[21] DIECKMANN K, GEORG D, ZEHETMAYER M, BOGNER J, GEORGOPOULOS $\mathrm{M}$ et al. LINAC based stereotactic radiotherapy of uveal melanoma: 4 years clinical experience. Radiother Oncol 2003; 67: 199-206.

[22] MEYER A, LÉVY C, BLONDEL J, D'HERMIES F, FRAU $\mathrm{E}$ et al. [Optic neuropathy after proton-beam therapy for malignant choroidal melanoma]. J Fr Ophtalmol 2000; 23: 543-553.

[23] SEDDON JM, GRAGOUDAS ES, EGAN KM, GLYNN RJ, HOWARD $S$ et al. Relative survival rates after alternative therapies for uveal melanoma. Ophthalmology 1990; 97: 769-777.

[24] GHAZI NG, KETCHERSIDE CS, SHEEHAN J, CONWAY BP. Gamma knife radiosurgery for uveal melanoma ineligible for brachytherapy by the Collaborative Ocular Melanoma Study criteria. Open Access Surg 2008; 1: 21-24. https://doi. org/10.2147/OAS.S3654

[25] FURDOVA A, SRAMKA M, CHORVATH M, KRALIK G, KRASNIK V et al. Stereotactic radiosurgery in intraocular malignant melanoma--retrospective study. Neuro Endocrinol Lett 2014; 35: 28-36.

[26] ADAMS KS, ABRAMSON DH, ELLSWORTH RM, HAIK $B G, B E D F O R D M$ et al. Cobalt plaque versus enucleation for uveal melanoma: comparison of survival rates. Br J Ophthalmol 1988; 72: 494-497.

[27] SINGH AD, SHIELDS CL, SHIELDS JA. Prognostic factors in uveal melanoma. Melanoma Res 2001; 11: 255-263.

[28] FURDOVA A, SLEZAK P, CHORVATH M, WACZULIKOVA I, SRAMKA $M$ et al. No differences in outcome between radical surgical treatment (enucleation) and stereotactic radiosurgery in patients with posterior uveal melanoma. Neoplasma 2010; 57: 377-381.

[29] AUGSBURGER JJ, GAMEL JW. Clinical prognostic factors in patients with posterior uveal malignant melanoma. Cancer 1990; 66: 1596-1600.

[30] KOUTSANDREA C, MOSCHOS MM, DIMISSIANOS M, GEORGOPOULOSG,LADASI Ietal.Metastasis rates and sites after treatment for choroidal melanoma by proton beam irradiation or by enucleation. Clin Ophthalmol 2008; 2: 989-995. 
[31] SUESSKIND D, SCHEIDERBAUER J, BUCHGEISTER M, PARTSCH M, BUDACH et al. Retrospective evaluation of patients with uveal melanoma treated by stereotactic radiosurgery with and without tumor resection. JAMA Ophthalmol 2013; 131: 630-637. https://doi.org/10.1001/jamaophthalmol.2013.697

[32] TRIOZZI PL, SINGH AD. Adjuvant Therapy of Uveal Melanoma: Current Status. Ocul Oncol Pathol 2014; 1: 54-62. https://doi.org/10.1159/000367715

[33] FURDOVA A, SRAMKA M, CHORVATH M, KRALIK G, FURDA et al. Clinical experience of stereotactic radiosurgery at a linear accelerator for intraocular melanoma. Melanoma Res 2017; 27: 463-468. https://doi.org/10.1097/ CMR.0000000000000364

[34] SHIELDS CL, KALIKI S, FURUTA M, FULCO E, ALARCON C et al. American Joint Committee on Cancer classification of posterior uveal melanoma (tumor size category) predicts prognosis in 7731 patients. Ophthalmology 2013; 120: 2066-2071. https://doi.org/10.1016/j.ophtha.2013.03.012
[35] KANG DW, LEE SC, PARK YG, CHANG JH. Longterm results of Gamma Knife surgery for uveal melanomas. J Neurosurg 2012; 117 Suppl: 108-114. https://doi. org/10.3171/2012.8.GKS121002

[36] ARNETT ALH, REYNOLDS MM, PULIDO JS, PARNEY IF, LAACK NN. Gamma Knife Stereotactic Radiosurgery for the Treatment of Primary and Metastatic Ocular Malignancies. Stereotact Funct Neurosurg 2017; 95: 363-368. https:// doi.org/10.1159/000478271

[37] MORI T, SUKEDA A, SEKINE S, SHIBATA S, RYO E et al. SOX10 Expression as Well as BRAF and GNAQ/11 Mutations Distinguish Pigmented Ciliary Epithelium Neoplasms From Uveal Melanomas. Invest Ophthalmol Vis Sci 2017; 58 : 5445-5451. https://doi.org/10.1167/iovs.17-22362

[38] HORKOVICOVA K, MARKUS J, KRCOVA I, BABAL P, KOBZOVA D et al. [THE BRAF MUTATION AND THE POSSIBILITIES OF UVEAL MELANOMA METASTASING PROGNOSTIC MARKERS IDENTIFICATION]. Cesk Slov Oftalmol 2016; 72: 149-156. 


\section{Uveal melanoma survival rates after single dose stereotactic radiosurgery}

A. FURDOVA ${ }^{1, *}$, P. BABAL ${ }^{2}$, D. KOBZOVA ${ }^{2}$, P. ZAHORJANOVA ${ }^{1}$, K. KAPITANOVA $^{1}$, M. SRAMKA ${ }^{3}$, G. KRALIK ${ }^{4}$, R. FURDA $^{5}$, V. KRASNIK ${ }^{1}$

\section{Supplemental Material}

Suppl. Table 1. Follow-up in group of 170 patients.

\begin{tabular}{|c|c|c|c|c|c|c|c|c|c|}
\hline $\begin{array}{l}\text { Follow-up } \\
\text { Period }\end{array}$ & $\begin{array}{c}\text { \# of Survived } \\
\text { in LTS }\end{array}$ & $\begin{array}{c}\text { \# of Survived } \\
\text { in MTS }\end{array}$ & $\begin{array}{c}\text { \# of Survived } \\
\text { in STS }\end{array}$ & $\begin{array}{c}\text { Total of } \\
\text { Survived }\end{array}$ & $\begin{array}{c}\text { \# of Died } \\
\text { LTS }\end{array}$ & $\begin{array}{c}\text { \# of Died in } \\
\text { MTS }\end{array}$ & $\begin{array}{c}\text { \# of Died in } \\
\text { STS }\end{array}$ & $\begin{array}{c}\text { Total of } \\
\text { Died }\end{array}$ & $\begin{array}{c}\text { Grand } \\
\text { Total }\end{array}$ \\
\hline 1 quarter & 3 & 12 & 5 & 20 & & & & & 20 \\
\hline 4 quarters & 6 & 12 & 2 & 20 & & 5 & 1 & 6 & 26 \\
\hline 8 quarters & 4 & 12 & 4 & 20 & 2 & 1 & 1 & 4 & 24 \\
\hline 12 quarters & 2 & 9 & 2 & 13 & & 5 & 1 & 6 & 19 \\
\hline 16 quarters & 7 & 18 & 7 & 32 & 1 & & & 1 & 33 \\
\hline 20 quarters & & 3 & 1 & 4 & & 1 & & 1 & 5 \\
\hline 24 quarters & 1 & 2 & 6 & 9 & & & 1 & 1 & 10 \\
\hline 28 quarters & 2 & 2 & & 4 & & 1 & & 1 & 5 \\
\hline 32 quarters & 1 & 6 & & 7 & & & 1 & 1 & 8 \\
\hline 36 quarters & & & 3 & 3 & & 1 & 1 & 2 & 5 \\
\hline 40 quarters & 1 & 4 & & 5 & & 1 & 1 & 2 & 7 \\
\hline 44 quarters & & & & & & & 1 & 1 & 1 \\
\hline 52 quarters & 3 & 1 & 1 & 5 & & & & & 5 \\
\hline 56 quarters & 1 & & & 1 & & & & & 1 \\
\hline 60 quarters & & 1 & & 1 & & & & & 1 \\
\hline Grand Total & 31 & 82 & 31 & 144 & 3 & 15 & 8 & 26 & 170 \\
\hline
\end{tabular}

Abbreviations: LTS - Large Tumor Size; MTS - Median Tumor Size; STS - Small Tumor Size. 